\title{
Developing and validating an isotrigon texture discrimination task using Amazon Mechanical Turk
}

\author{
John WG Seamons ${ }^{1 *}$, Marconi S Barbosa ${ }^{1}$, Jonathan D Victor ${ }^{2}$, Dominique Coy ${ }^{1}$, Ted Maddess ${ }^{1}$ \\ From 24th Annual Computational Neuroscience Meeting: CNS*2015 \\ Prague, Czech Republic. 18-23 July 2015
}

The human visual system must employ mechanisms to minimize informational redundancy whilst maintaining that which is behaviorally relevant $[1,2]$. Previous research has concentrated on two-point correlations via spatial frequency and orientation tuning. Higher-order correlations are less studied, but they may inform us about cortical functioning [3]. Isotrigon textures can be used to probe the sensitivity of the human visual system as their struc- ture is exclusively due to $4^{\text {th }}$ and higher-order spatial correlations [4]. Although artificially generated, the same features that give isotrigons salience also create salience in natural images [2]. We implemented an isotrigon discrimination task using the crowdsourcing platform Amazon Mechanical Turk (mTurk) [5]. An important secondary aim was to evaluate the suitability of mTurk for visual psychometric studies as very few exist [6].
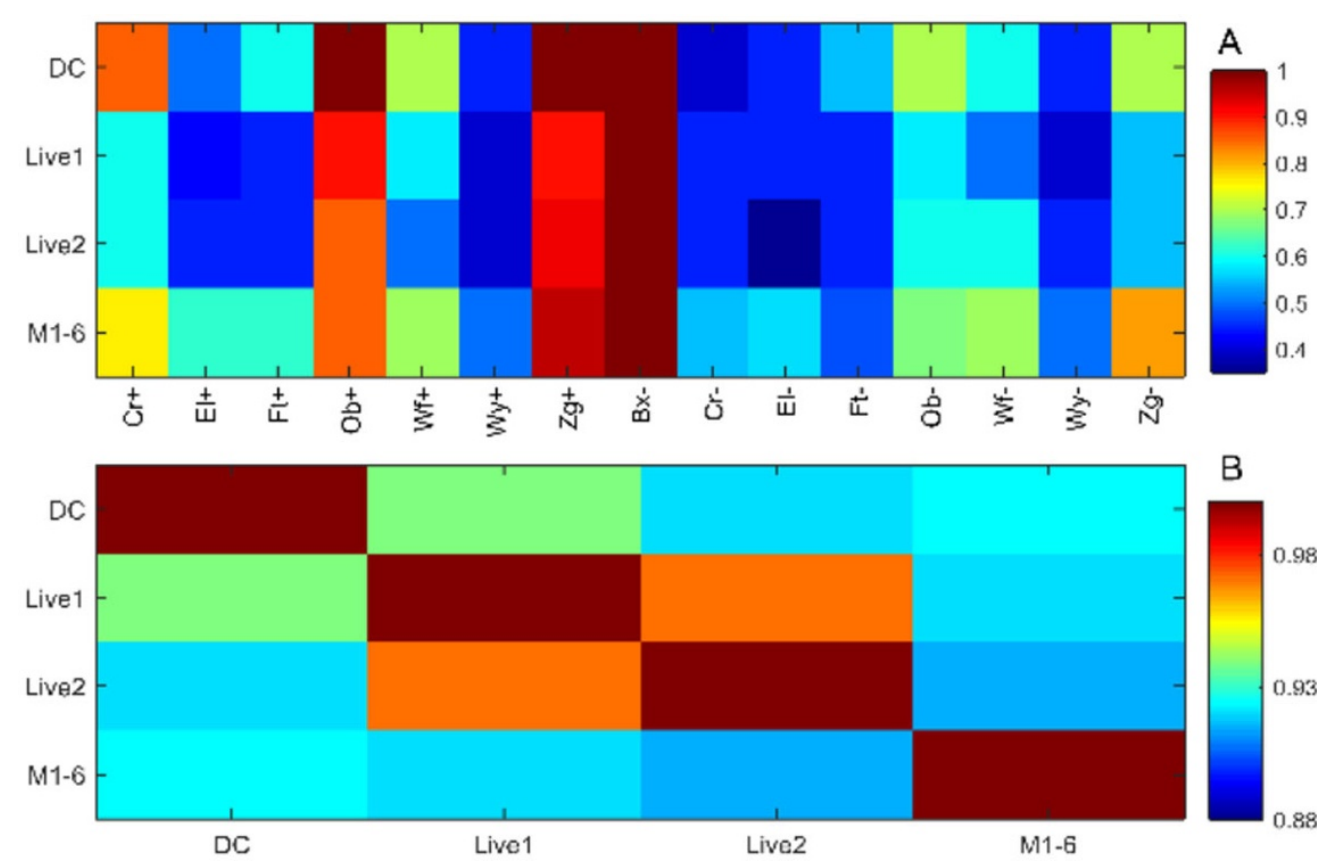

Figure 1 1A: Color map of median texture discrimination performance versus isotrigon texture type. Lab datasets DC (84 HITs) and M1-6 (270 HITs). mTurk datasets Live1 (480 HITs) and Live2 (480 HITs). 1B: Pearson's correlation coefficients between datasets (abbreviations as above).

\footnotetext{
* Correspondence: john.seamons@anu.edu.au

'Eccles Institute for Neuroscience, John Curtin School of Medical Research,

ANU, Canberra, ACT 0200, Australia

Full list of author information is available at the end of the article
} 
960 HITs were uploaded to mTurk and 121 naïve subjects participated. Based on data quality, 91\% of HITs were retained at a cost of $\$ 0.132$ AUD per HIT. The mTurk data was compared to two supervised lab datasets. Lab and mTurk performance functions were very similar (Figure 1A) and highly correlated (Figure 1B). Bland-Altman plots were examined and the mean lab/ mTurk coefficient of repeatability was $15.5 \%$. Factor analysis was performed on the combined data and 2 principal factors were identified. Previous studies support that the number of mechanisms is less than 10 [7] and more likely $2-4[8,9]$. The congruence between the lab and mTurk data is striking considering the unsupervised mode of delivery. In conclusion, mTurk is an underutilized platform for visual psychometric research which can produce data of comparable quality to lab samples at reduced cost and increased scale.

\section{Authors' details}

${ }^{1}$ Eccles Institute for Neuroscience, John Curtin School of Medical Research, ANU, Canberra, ACT 0200, Australia. ${ }^{2}$ Department of Neurology \&

Neuroscience, Weill Cornell Medical College, 1300 York Ave, New York 10021, USA.

Published: 18 December 2015

\section{References}

1. H Barlow: Redundancy reduction revisited. Network 2001, 12(3):241-253.

2. G Tkacik, JS Prentice, JD Victor, V Balasubramanian: Local statistics in natural scenes predict the saliency of synthetic textures. Proc Natl Acad Sci U S A 2010, 107(42):18149-18154.

3. JD Victor: Isodipole Textures: A Window on Cortical Mechanisms of Form Processing. In Early Vision and Beyond. MIT Press;Papathomas TVC, C.; Gorea, A; Kowler, E 1995:99-107.

4. T Maddess, Y Nagai, AC James, A Ankiewcz: Binary and ternary textures containing higher-order spatial correlations. Vision Res 2004, 44(11):1093-1113.

5. W Mason, S Suri: Conducting behavioral research on Amazon's Mechanical Turk. Behavior research methods 2012, 44(1):1-23.

6. J Freeman, CM Ziemba, DJ Heeger, EP Simoncelli, JA Movshon: A functional and perceptual signature of the second visual area in primates. Nature neuroscience 2013, 16(7):974-981.

7. RR Taylor, T Maddess, Y Nagai: Spatial biases and computational constraints on the encoding of complex local image structure. J Vis 2008, 8(7):19 11-13.

8. T Maddess, Y Nagai: Discriminating isotrigon textures [corrected]. Vision Res 2001, 41(28):3837-3860.

9. T Maddess, Y Nagai, JD Victor, RR Taylor: Multilevel isotrigon textures. J Opt Soc Am A Opt Image Sci Vis 2007, 24(2):278-293.

doi:10.1186/1471-2202-16-S1-P278

Cite this article as: Seamons et al:: Developing and validating an isotrigon texture discrimination task using Amazon Mechanical Turk. BMC Neuroscience 2015 16(Suppl 1):P278.

\section{Submit your next manuscript to BioMed Central and take full advantage of:}

- Convenient online submission

- Thorough peer review

- No space constraints or color figure charges

- Immediate publication on acceptance

- Inclusion in PubMed, CAS, Scopus and Google Scholar

- Research which is freely available for redistribution

Submit your manuscript at www.biomedcentral.com/submit
C Biomed Central 